\title{
Strategi Guru Membantu Siswa dalam Melakukan Penyesuaian Sikap: Studi pada Siswa Tahun Pertama Sekolah Dasar Pedesaan
}

\author{
Syamsul Ghufron ${ }^{1}$, Afib Rulyansah ${ }^{\circledR}{ }^{\circledR}$, Rizki Ananda ${ }^{3}$, Fadhilaturrahmi $^{4}$ \\ Pendidikan Profesi Guru Dalam Bidang Studi Guru Sekolah Dasar, Universitas Nahdlatul \\ Ulama Surabaya, Indonesia(1); Pendidikan Guru Sekolah Dasar, Universitas Nahdlatul \\ Ulama Surabaya, Indonesia(2); Pendidikan Guru Sekolah Dasar, Universitas Pahlawan \\ Tuanku Tambusai, Indonesia(3) \\ DOI: $\underline{10.31004 / o b s e s i . v 6 i 4.2345}$
}

\begin{abstract}
Abstrak
Siswa kelas satu sekolah dasar belum terbiasa dengan suasana di kelas barunya sehingga perlu penyesuaian dalam bersikap. Sangat terbatas sekali riset yang membahas tentang strategi guru membantu siswa menyesuaikan diri pada tahun pertama sekolah dasar khususnya daerah pedesaan yang memiliki sejumlah tantangan. Penelitian grounded theory, salah satu tradisi penelitian kualitatif, digunakan untuk mengembangkan penelitian ini. Total ada 18 siswa SD yang mulai tahun pertama masuk sekolah tahun ini. Data observasi dikumpulkan dari para peserta. Setelah mendapatkan semua izin yang diperlukan dari sekolah setempat, anak-anak yang berpartisipasi, guru, dan orang tua, dilakukan observasi. Analisis data dilakukan dalam tiga tahap: Open Coding, Axial Coding, dan Selective Coding. Hasil riset ini menunjukkan bahwa pada konteks sekolah dasar pedesaan, guru dapat melakukan 10 strategi membantu siswa melakukan penyesuaian sikap. Strategi-strategi tersebut adalah aturan untuk ijin berbicara, komunikasi interpersonal, pemberian pujian dan self evaluation, menjanjikan reward, pemberian tugas yang dikerjakan bersama "lawan", guru, atau mandiri, menanamkan konsep sharing is caring, pemberian contoh dan acuan dari teman sebaya, dan melihati siswa.

Kata Kunci: siswa kelas rendah; sekolah dasar; strategi penyesuaian sikap.
\end{abstract}

\begin{abstract}
First grade elementary school students who are not used to the atmosphere in their new class so they need to adjust their minds. Very limited research that discussed teacher strategies to help students adjust to the first year of primary school, especially in rural areas that have many challenges. Grounded theory research, one of the traditions of qualitative research, was used to develop this research. There were a total of 18 elementary school students starting their first year of school this year. Observational data were collected from the participants. After obtaining all the necessary permits from the local school, the participating children, teachers, and parents were observed. Data analysis was carried out in three stages: Open Coding, Axial Coding, and Selective Coding. The results of this study indicate that in the context of rural elementary schools, teachers can implement 10 strategies to help students make attitude adjustments. These strategies are rules for permission to speak, interpersonal communication, giving praise and self-evaluation, gifts, giving assignments to be done with "opponents", teachers, or independently, instilling the concept of caring, giving examples and praise from peers, and observing student.
\end{abstract}

Keywords: lower grade students; primary school; attitude adjustment strategy.

Copyright (c) 2022 Syamsul Ghufron, et al.

$\triangle$ Corresponding author:

Email Address : afib.rulyansah0417@unusa.ac.id (Surabaya, Jawa Timur, Indonesia)

Received 28 November 2022, Accepted 20 February 2022, Published 28 February 2022 


\section{PENDAHULUAN}

Interaksi antar pribadi terjadi di sekolah, khusus di kelas. Oleh karena itu, penyesuaian sikap diperlukan agar terjadi hubungan yang sehat antar pribadi. Hubungan guru dan siswa dapat digolongkan dalam interaksi interpersonal. Interaksi ini tidak terjadi dengan hubungan yang berlevel sama. Guru merupakan orang dewasa yang harus membuat anak didiknya mampu menyesuaikan diri dengan aturan dan norma sekolah serta kelas. Dalam posisi ini, guru menerapkan proses scaffolding yang bernama kontingensi. Kontingensi ini menuntut guru untuk mengambil kontrol terhadap aktivitas siswa (Sun et al., 2021; Tabatabaei \& Assefi, 2012).

Interaksi guru dan siswa yang sehat menghasilkan social engagement. Keterhubungan sosial sangat erat hubungannya dengan keterlibatan secara akademik dan non-akademik ( $\mathrm{Ng}$ \& Chu, 2021). Hubungan guru dan siswa menjadi sangat penting untuk diperhatikan agar dapat mengembangkan pembelajaran bermakna (Zydziunaite et al., 2021) sehingga berdampak positif pada aktivitas sosial (Aspelin et al., 2021), afektif dan akademik siswa (Ayuwanti et al., 2021). Siswa menjadi lebih matang dalam bersosialisasi bila dibekali dengan interaksi secara sehat bersama guru. Guru dapat memberikan pengetahuan dan latihan bagaiamana cara berkomunikasi dan bersikap secara baik dan santun (Rulyansah, 2021; Rulyansah, Asmarani, \& Mariati, 2022; Rulyansah, Asmarani, Mariati, et al., 2022).

Transisi dari taman kanak-kanak ke sekolah dasar merupakan salah satu tahapan kehidupan yang penting bagi anak. Kesuksesan pengalaman di kelas awal masa sekolah dapat dijadikan prediksi untuk kesuksesan kehidupan sekolah anak-anak di masa mendatang (Cook et al., 2017). Namun, anak dihadapkan pada lingkungan sosial, akademik, perilaku, serta guru yang berbeda daripada yang sebelumnya (Coşkun \& Kara, 2020a; Dockett \& Perry, 2013; Perry et al., 2013). Hal ini menjadi tantangan tidak hanya bagi anak, tetapi juga bagi orang tua mereka. Oleh karena itu, diperlukan penyesuaian sikap oleh anak-anak tersebut dengan dibantu oleh guru.

Guru di sekolah dasar pedesaan, diharapkan dapat membantu siswa melakukan penyesuaian sikap dengan usaha yang lebih banyak daripada guru yang berada di lingkungan perkotaan. Keadaan pendidikan di pedesaan memiliki sejumlah keterbatasan, diantaranya komposisi dan kehadiran guru yang kurang proporsional (KIAT Guru, 2019), sistem pendidikan yang hampir tidak berkembang, infrastruktur yang kurang memadai, rendahnya kesejahteraan ekonomi, orang tua yang tidak memiliki sarana pendukung untuk pendidikan anaknya, dan sebagainya (Huguette, 2021). Berkebalikan dengan hal tersebut, ternyata siswa pedesaan dan perkotaan memiliki tingkat pencapaian yang sebanding di beberapa bidang pembelajaran yang diuji (Tayyaba, 2012). Oleh karena itu, siswa pada sekolah pedesaan perlu juga mendapat perhatian agar pembelajaran menjadi lebih manusiawi.

Sejumlah state of the art research terkait interaksi guru dan siswa telah dilakukan, namun belum banyak riset yang membahas topik tersebut dalam konteks strategi guru untuk membantu siswa kelas satu sekolah dasar pedesaan dalam melakukan penyesuaian sikap. Pada jenjang Pendidikan Anak Usia Dini (PAUD), Wang et al. (2019) mengembangkan metode pembelajaran hybrid berbasis teknologi komputer dalam upaya mengembangkan ketertarikan belajar serta kemampuan siswa. Pada level pendidikan sekolah dasar, Coşkun \& Kara (2020b) melakukan investigasi terkait strategi penyesuaian sikap siswa tahun pertama di sekolah dasar, namun tidak ada keterangan yang fokus pada sekolah dasar pedesaan. Aspelin et al. (2021) melaksanakan riset yang melibatkan guru dari anak berkebutuhan khusus dan guru mengalami pergeseran persepsi dari awalnya yang lebih fokus pada strategi pengajaran menuju hubungan yang terbuka antara siswa dan guru. Jenjang selanjutnya, Liu \& Gillies (2021) menyimpulkan bahwa interaksi guru dan siswa SMA di Cina dalam pembelajaran bahasa, dapat dimediasi melalui pertanyaan-pertanyaan yang diberikan guru yang berbentuk pertanyaan referensial (jawaban diperoleh dengan cara menalar, menganalisa, mengevaluasi, dan menformulasikan ide). Terakhir, pada jenjang pendidikan tinggi, melalui riset korelasional, Jafari \& Asgari (2020), melakukan prediksi terhadap prestasi akademik 
mahasiswa berdasarkan iklim kelas, interaksi dosen dan mahasiswa, serta motivasi akademik. Tahun berikutnya, Zhang (2021) meningkatkan kualitas hubungan dosen dan mahasiswa perguruan tinggi melalui pendekatan kolaborasi yang memanfaatkan mobile internet technology.

Tujuan dari riset ini adalah untuk mengembangkan teori yang menghasilkan penjelasan tentang strategi guru membantu siswa kelas satu sekolah dasar pedesaan untuk dapat melakukan penyesuaian sikap terhadap aturan dan budaya di sekolah. Artikel ini disusun menjadi sejumlah bagian. Bagian Metode membahas desain penelitian, partisipan, instrumen penelitian, dan analisis data. Dalam Bagian Hasil, artikel ini menyajikan dan mendiskusikan hasil empiris dari penelitian ini. Bagian Kesimpulan merangkum temuan utama penelitian dan menyoroti kontribusi penelitian ini terhadap literatur yang ada. Bagian ini juga memberikan rekomendasi untuk penelitian masa depan.

\section{METODOLOGI}

Teori penjelas akan dikembangkan dalam penelitian ini karena mencoba menjelaskan bagaimana siswa kelas satu beradaptasi dengan lingkungan kelas ketika mereka mulai sekolah dasar. Oleh karena itu, penelitian ini dibuat dengan menggunakan penelitian grounded theory, yang merupakan tradisi penelitian kualitatif. Kepadatan konseptual dapat dikembangkan dan hubungan antar ide dapat ditemukan melalui analisis data menggunakan grounded theory. Generalisasi secara tentatif atau asumsi teoretis dapat dibangun hanya ketika pengetahuan yang ditemukan mencapai titik jenuh. Karakteristik yang paling menonjol dari metodologi ini adalah keterbukaan terhadap ide-ide yang muncul dari data. Hal ini melindungi pembangunan teori agar lebih independen.

Convenience sampling digunakan untuk merekrut peserta karena tujuan utama penelitian ini adalah untuk membuat hipotesis tentang bagaimana penyesuaian siswa kelas satu ke sekolah melibatkan interaksi antara mereka dan guru mereka. Dalam convenience sampling, peneliti menentukan jumlah sampel yang diambil dari populasi (Ocak \& Karakuyu, 2022). Convenience sampling, salah satu teknik pemilihan non-acak, digunakan untuk memilih siswa sekolah dasar yang berusia 6 tahun dan sudah mulai Kelas 1.

Sekolah dasar dikunjungi dan guru sekolah dasar Kelas 1 dihubungi setelah mendapatkan izin resmi dari pemerintah setempat untuk melakukan pengumpulan data. Hanya ada satu guru sekolah dasar yang setuju untuk berpartisipasi dalam penelitian ini. Ada permintaan agar mereka datang ke kelas bersama dua kali seminggu, dan mereka semua setuju. Setelah mendapat izin tertulis dari orang tua, penjelasan menyeluruh tentang tujuan penelitian disampaikan kepada mereka. Hasilnya, sampel penelitian termasuk 18 siswa kelas satu yang telah menyelesaikan Kelas 1.

Sebelum hari pertama sekolah, Guru menghiasi dan menghiasi kelas dengan bagan tentang angka dan simbol alfabet. Taman bermain mengambil seperlima dari ruang kelas. Taman bermain itu dilapisi karpet dengan lapisan bantalan yang tebal. Di taman bermain, ada mainan, balok, boneka, dan permainan. Itu dipisahkan dari ruang kelas lainnya oleh penghalang setinggi 35 atau 40 sentimeter. Guru memberi tahu anak-anak bahwa sepatu tidak diizinkan di taman bermain. Selain itu, ada total $18 \mathrm{kursi}$ di ruangan itu. Guru sering mengatur meja secara berurutan, meskipun kadang-kadang ia menggabungkan tiga meja dan membentuk kelompok.

Riset dilakukan setelah mendapat persetujuan resmi dari pihak sekolah dan orang tua siswa yang menjadi partisipan penelitian. Nama siswa dikodekan dalam bentuk "Siswa 1", "Siswa 2" dan seterusnya, untuk menjaga kerahasiaan informasi partisipan. Semua catatan lapangan yang dihimpun peneliti kemudian dibagikan juga kepada guru dan orang tua siswa.

Data kejadian dan strategi guru dikumpulkan melalui pengamatan pada partisipan yang ada di kelas. Para peneliti telah mendapatkan izin dari guru dan orang tua siswa untuk melakukan riset selama 3 bulan. Pengamatan di kelas dilakukan 2 kali dalam sepekan. Catatan 
lapangan dikumpulkan selama pengamatan. Pengamatan dilakukan selama satu jam pelajaran.

Ada perbedaan besar antara metode penelitian kuantitatif dan kualitatif dalam hal ide pengambilan sampel. Sampling kualitatif, di sisi lain, berfokus pada kejadian daripada kuantitas peserta dalam penelitian kuantitatif. Akibatnya, penelitian kualitatif didorong oleh teori karena didasarkan pada kejadian. Acara, di sisi lain, membutuhkan banyak data.

Pengambilan sampel teoritis sangat penting dalam penelitian ini, yang dibangun menggunakan grounded theory. Dalam hal penelitian, pengambilan sampel adalah proses berkelanjutan yang berubah seiring waktu. Konsep yang ditemukan melalui analisis data digunakan untuk memandu pengambilan sampel. Sebagai cara untuk membandingkan dan mengkontraskan kejadian, digunakan sampling teoretis. Tidak ada ide atau kategori baru yang dapat ditemukan ketika peristiwa dan interaksi tindakan yang sama terjadi berulang kali dalam grounded theory. Sekarang saatnya untuk berhenti mengumpulkan data melalui observasi partisipan.

Open Coding, axial coding, dan selective coding digunakan dalam tiga proses berturutturut untuk menganalisis data (Hung et al., 2021; Xiang et al., 2021; Zhou et al., 2021). Pengumpulan data dan analisis data merupakan aktivitas yang saling terkait dalam grounded theory. Analisis dimulai setelah kumpulan data pertama dikumpulkan. Secara iteratif, catatan lapangan yang ditulis dibacakan dari awal sampai akhir (Zhou et al., 2021). Setelah setiap pengamatan, data dianalisis. Analisis data grounded theory sangat bergantung pada perbandingan. Setiap bagian data terus dibandingkan dengan informasi yang diperoleh sebelumnya (Chirinda, 2021). Proses tahapan analisis data diilustrasikan pada Gambar 1.

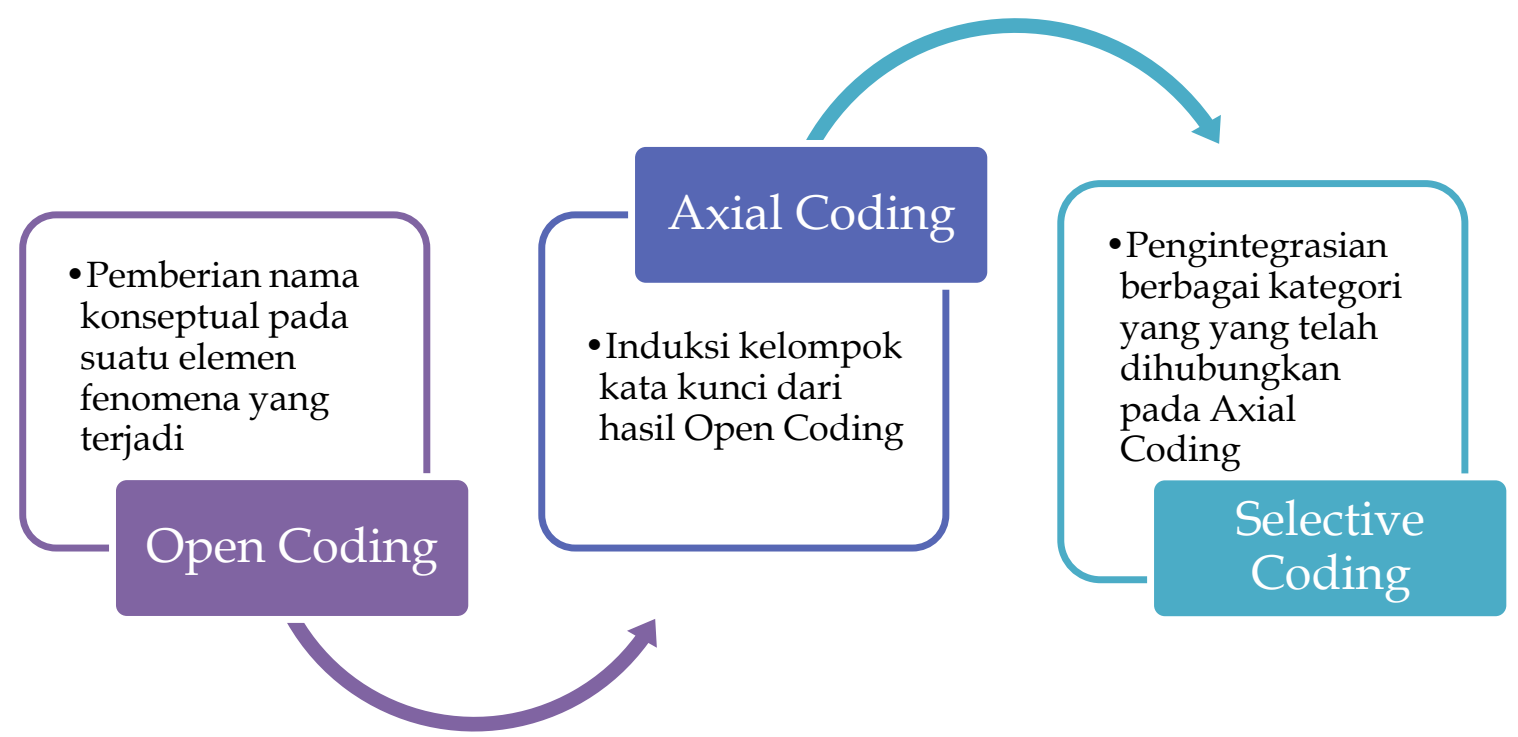

Gambar 1. Tahap Analisis Data

Open Coding adalah proses di mana seorang peneliti dapat mengurangi sebagian besar data menjadi jumlah unit yang lebih mudah dikelola, menyelidiki dan mengidentifikasi peristiwa, objek, tindakan, atau interaksi (Samuel \& Dudu, 2018). Karena teori tidak dapat didasarkan pada kejadian atau situasi nyata, analisis data dilakukan dengan menggunakan ide. Selain itu, ide adalah bagian bangunan dari sebuah teori, itulah sebabnya mereka sangat penting. Ada fokus yang kuat pada peristiwa dan kejadian sebagai penanda atau lambang fenomena yang lebih besar. Akibatnya, kejadian atau kejadian mungkin diberi nama konseptual untuk menggambarkan salah satu elemen fenomena. Pendekatan perbandingan terus menerus dan pembacaan berulang digunakan untuk mengidentifikasi dan memberi nama ide dan dimensinya dalam pengkodean terbuka. Akibatnya, data diabstraksikan dan dipecah menjadi bagian-bagian yang lebih kecil dan lebih mudah dikelola. Pengodean terbuka juga melibatkan pengkategorian ide. Kategori, yang lebih luas dan lebih abstrak daripada ide, 
digunakan untuk menghubungkan konsep satu sama lain. Untuk membangun logika induktif, pertama-tama perlu mengidentifikasi dan kemudian mengelompokkan ide ke dalam kategori, kata yang lebih umum. Konsep dikategorikan bersama dengan dimensi dan karakteristiknya:

Pada fase Axial Coding, kategori diinduksi menggunakan pengelompokan kata kunci dari jawaban yang diperoleh dalam Open Coding (Chirinda, 2021). Axial Coding berguna dalam membangun hubungan antara berbagai kategori dan subkategori (Azwar et al., 2021). Kategori dan subkategori dihubungkan dalam pengkodean aksial, tahap kedua pemrosesan data, berdasarkan atribut dan dimensinya. Dalam Open Coding, sumbu kategori ditentukan, dan pengkodean dilakukan di sekitarnya. Kategori dan atribut serta dimensinya ditulis dalam pengkodean aksial. Aksi-interaksi, keadaan dan konteks serta efek ditemukan sebagai satu set pola.

Selective Coding adalah langkah metodis untuk mengintegrasikan kategori-kategori yang telah dihubungkan melalui Axial Coding dan mengelaborasinya ke dalam teori (Kim et al., 2021; Oswald \& Zhao, 2021). Pada tahap ini, kategori penelitian kunci diidentifikasi, asosiasi dengan kategori lain didefinisikan, dan kategori dijelaskan. Proses ini dapat mengembangkan jenis teori baru tentang masalah penelitian dengan membentuk dan mewujudkan hubungan antara keduanya. Semua kategori digabungkan, dan pengalaman peserta diringkas untuk diturunkan dengan Selective Coding kategori inti yang mewakili tema sentral penelitian (Park, 2021).

\section{HASIL DAN PEMBAHASAN}

\section{Peristiwa 1 Aturan untuk ijin berbicara}

Pada hari pertama masuk kelas satu, guru menjelaskan sejumlah aturan yang berlaku di kelas, salah satunya adalah aturan untuk hak berbicara. Guru menjelaskan kepada murid bahwa bila semua siswa berbicara bersamaan maka suasana akan gaduh dan semua siswa tidak akan menangkap pesan apa yang ingin disampaikan. Guru menetapkan aturan bahwa siswa yang ingin berbicara secara formal dengan guru atau teman sekelas, harus mengangkat tangan terlebih dahulu. Setelah guru mengizinkan berbicara, siswa boleh mengutarakan apa yang ingin disampaikan.

Ketika pelajaran menggambar, siswa 4 dan siswa 9 langsung bertanya kepada guru terkait pertanyaan yang sama, yaitu menggambar tentang apa. Padahal, tema menggambarnya juga belum disampaikan oleh guru. Guru mengingatkan bahwa di kelas ada aturan yang harus kita patuhi, yaitu mengangkat tangan untuk izin berbicara. Siswa 4 dan siswa 9 menyampaikan mereka lupa tentang hal itu. Pada konteks ini, guru berusaha untuk melatih siswa agar menghormati orang lain Ketika berbicara.

\section{Peristiwa 2 Komunikasi interpersonal}

Komunikasi interpersonal digunakan untuk menjelaskan kesalahan, mengurangi sikap yang agresif dan mendapat approval dari siswa, self evaluation, dan mengembangkan rasa memiliki. Sejumlah kejadian dapat menggambarkan fungsi-fungsi komunikasi interpersonal tersebut.

\section{Peristiwa 2a Menjelaskan kesalahan}

Pembelajaran di kelas satu sekolah dasar menerapkan pendekatan tematik. Hal ini mengintegrasikan sejumlah bidang studi yang dikaitkan dengan tema. Pembelajaran bilangan cacah diajarkan pada muatan pelajaran matematika. Pada pembelajaran tersebut, guru memanfaatkan Lego. Karena keterbatasan media pembelajaran, guru membentuk kelompok dan meminta siswa bersama kelompoknya untuk Menyusun angka 1 sampai 5 menggunakan Lego tersebut. Terdapat 5 kelompok yang sudah terbentuk. Siswa 12 dari kelompok C justru membuat sebuah mainan menyerupai menara. Hal ini menunjukkan siswa 12 tidak mematuhi instruksi yang diberikan guru sehingga guru mendekat dan berkomunikasi secara personal 
untuk menjelaskan bahwa hal ini kurang sesuai dengan aturan yang ada dan hal ini boleh dilakukan ketika pembelajaran telah selesai dilaksanakan. Siswa 12 memahami dan mengikuti arahan yang diberikan guru.

\section{Peristiwa 2b Mengurangi sikap agresif dan mendapat approval dari siswa}

Semua siswa sedang bermain bersama dan mereka tampak menikmati kegiatan saat istirahat. Namun, perilaku agresif Siswa 8 terhadap siswa 4 merusak suasana positif di dalam kelas. Siswa 8 ingin menjadi pemimpin kelompok, tetapi Anak 4 menyetujui hal itu. Guru memperingatkan Siswa 8 dan mengatakan dia akan mengawasinya. Siswa 8 menyesali perilaku agresifnya. Suasana kelas kembali kondusif. Guru memanggil Siswa 8 dan meminta agar Kembali ke tempat duduknya. Ketika Siswa 8 datang ke guru, guru mulai menjelaskan mengapa perilakunya salah. Guru meminta siswa 8 untuk ikut membantu merapikan peralatan belajar di tempat duduknya

Pemintaan Siswa 8 untuk menjadi ketua kelompok dapat dipandang sebagai kebutuhannya untuk mendapatkan persetujuan. Ketika anggota kelompok tidak menyetujuai permintaan tersebut, Siswa 8 berusaha untuk tetap membuat siswa lain menerima sehingga tindakan Siswa 8 mengarah pada perilaku yang agresif. Guru menjalin komunikasi personal dan menasihati bahwa tindakan tersebut sangat membuat orang lain tidak nyaman. Dalam kasus ini, komunikasi guru secara personal kepada siswa dapat mengurangi bahkan meniadakan perilaku agresif serta mampu mendapat persetujuan anak untuk bekerja sama dengan orang lain dalam merapikan tempat belajar.

\section{Peristiwa 2c Mengembangkan rasa memiliki}

Pada saat jam istirahat, sejumlah siswa berbincang-bincang di beberapa tempat duduk yang dilengkapi dengan satu meja. Siswa 2, siswa 7, siswa 13, dan siswa 18 berbincangbincang sambil mencoret-coret meja. Hal ini diketahui oleh guru. Guru mendekat dan sedikit jongkok, kemudian menjelaskan bahwa kelas ini dihuni oleh siswa-siswa yang baik dan suka kebersihan. Siswa pun menyetujui hal itu. Guru kemudian menanyakan bahwa tindakan mencoret meja apakah tindakan baik. Semua siswa menjawab hal ini tidak baik.

Guru memiliki usaha dalam menanamkan moral anak. Guru mengawali perbincangan dengan beberapa siswa melalui penjelasan bahwa siswa-siswa ini sangat baik dan suka kebersihan, kemudian melanjutkan dengan pertanyaan mencoret-coret meja apakah tindakan yang baik. Dalam hal ini guru mencoba untuk menanamkan rasa memiliki kelas dan semua benda yang ada di dalamnya.

\section{Peristiwa 3 Pemberian pujian dan self evaluation}

Pada Peristiwa 2c, selain guru berusaha untuk menanamkan rasa memiliki, guru juga memberikan pujian disertai aktivitas mengevaluasi secara mandiri. Pemberian pujian diberikan dalam bentuk ungkapan bahwa siswa-siswa yang menempati kelas satu ini adalah siswa yang baik serta menyukai kebersihan. Di sisi lain, guru memberikan pertanyaan evaluasi berupa pertanyaan tentang apakah aktivitas mencoret-coret ini merupakan tindakan baik, yang tidak berlawanan dengan karakter mereka. Pertanyaan tersebut menuntun siswa untuk mengevaluasi diri sendiri dan secara kompak menjawab aktivitas mencoret-coret meja merupakan perilaku yang tidak baik.

\section{Peristiwa 4 Menjanjikan reward}

Guru meminta siswa untuk menggambar pada buku gambar masing-masing. Guru memberikan tema menggambar, yaitu lingkungan rumah. Guru berkeliling melihat proses siswa dalam menggambar. Siswa terlihat antusias dalam menggambar meskipun sejumlah siswa tampak bersantai dalam menggambar. Guru memberikan informasi bahwa terdapat hadiah menarik untuk 3 siswa yang menggambar dengan bagus. Sontak, semua siswa lebih serius dalam menggambar dan berkeinginan untuk segera menyelesaikannya. 
Guru menyampaikan akan segera kembali ke kelas setelah mengambil hadiah di ruang kantor guru. Meskipun, tidak ada kehadiran guru di kelas, suasana kelas tetap kondusif. Siswa terlihat masih konsentrasi menggambar dengan motivasi mendapatkan reward dari guru. Hal ini menunjukkan bahwa motivasi siswa menggambar tidak dipengaruhi oleh kehadiran guru. Namun, strategi ini tidak bisa berlangsung lama tanpa kehadiran guru

\section{Peristiwa 5 Pemberian tugas tipe 1: dikerjakan bersama dengan "lawan"}

Pada kesempatan lain, guru membagikan Lego dan membebaskan siswa untuk bermain. Guru duduk di kursi kerjanya untuk menyiabkan tugas yang akan dikerjakan di rumah. Siswa 4 membuat rumah-rumahan. Siswa 15 datang menghampiri Siswa 4 merobohkan rumah-rumahan yang telah di buat. Guru mendatangi Siswa 15 dan sedikit menegur. Guru menyampaikan bahwa hal ini salah dilanjutkan dengan menyakan perasaan Siswa 15 bila apa yang kamu dirusak oleh orang lain. Siswa 15 akhirnya memahami bahwa ini salah. Kemudian, guru meminta Siswa 4 dan Siswa 15 bekerja sama untuk membuat 1 rumah-rumahan. Hal ini memberikan dampak positif untuk melatih kerjasama diantara pihak yang sedang berseteru.

\section{Peristiwa 6 Pemberian tugas tipe 2: dikerjakan bersama dengan guru}

Pada Peristiwa $2 \mathrm{~b}$ sebelumnya telah dijelaskan bahwa melalui komunikasi personal, guru telah memperoleh persetujuan siswa. Di sisi lain, guru juga meminta kerja sama siswa tersebut dalam merapikan meja belajarnya. Permintaan untuk bekerja sama dengan guru, harus diawali dengan percakapan interpersonal yang hangat dan intens.

\section{Peristiwa 7 Pemberian tugas tipe 3: dikerjakan secara mandiri}

Guru meminta Siswa 12 untuk ke depan kelas dan melafalkan huruf yang ditulis di papan. Guru menulis huruf alfabet mula "A" sampai "Z". Siswa 12 telihat kesulitan untuk melafalkan huruf "R". Guru membantu dan memotivasi Siswa 12. Selama guru melakukan hal tersebut, siswa lain di kelas saling berbicara satu sama lainnya sehingga suasana kelas menjadi kurang kondusif. Guru meminta siswa untuk diam dan kelas kembali kondusif. Beberapa saat kemudian, para siswa kembali membuat kegaduhan lagi. Akhirnya, guru meminta semua siswa untuk mengerjakan Lembar Kegiatan Siswa (LKS) secara mandiri dan tidak boleh berdiskusi antar siswa. Suasana kelas menjadi lebih kondusif.

\section{Peristiwa 8 Konsep sharing is caring}

Siswa 7 mengambil 6 buku pada "Pojok baca" secara sekaligus. Siswa 9 mengambil sebuah buku di tempat yang sama kemudian duduk untuk membaca. Siswa 7 kemudian secara sepihak mengambil buku yang dibaca oleh Siswa 6. Kejadian ini diketahui oleh guru yang kemudian menjelaskan bahwa semua siswa harus berbagi dan menjelaskan betapa pentingnya berbagi sesuatu dengan siswa yang lain. Meskipun Siswa 7 tidak rela apabila buku dibagikan kepada Siswa 6, cara ini berhasil untuk menumbuhkan karakter untuk berbagi.

\section{Peristiwa 9 Pemberian contoh dan acuan dari teman sebaya}

Guru membagikan kertas HVS kosong dan meminta setiap siswa untuk menggambar mobil untuk siswa laki-laki dan bunga untuk siswa perempuan. Beberapa saat kemudian, guru berkeliling untuk memantau proses pengerjaan tugas yang diberikan. Guru berhenti di bangku Siswa 7 dan melihat bahwa dia menggambar dengan baik. Sontak, Siswa 1, Siswa 10, dan Siswa 16 menuju bangku Siswa 7 untuk melihat proses dan hasil menggambarnya. Dalam kejadian ini, siswa membutuhkan contoh riil yang berasal dari teman sekelasnya. Pemberian contoh langsung dari teman sekelas memberi dampak signifikan pada penyelesaian tugas.

\section{Peristiwa 10 Melihati siswa}

Pada area "Pojok Baca", terdapat alas karpet dan setiap siswa yang ingin memasuki area tersebut harus melepas alas kaki. Siswa 4 dengan sengaja tidak melepas sepatu saat 
mengambil buku di area tersebut. Hal ini diketahui oleh guru. Guru tidak memberi peringatan lisan. Guru hanya melihati siswa tersebut dengan muka data hingga dengan sendirinya Siswa 4 melepas alas kaki kemudian melanjutkan membaca di area tersebut. Strategi guru yang tidak memberi peringatan lisan namun justru menggunakan peringatan nonverbal terbukti efektif supaya siswa mematuhi peraturan kelas yang telah disepakati bersama.

Guru menggunakan berbagai strategi untuk membantu siswa menyesuaikan diri pada tahun pertama di sekolah dasar. Ketika pertemuan pertama, guru harus menyampaikan semua peraturan yang diberlakukan di kelas, salah satunya adalah aturan untuk ijin berbicara. Selama proses pembelajaran, guru dapat menerapkan komunikasi interpersonal kepada siswa, baik secara individu maupun kelompok siswa. Komunikasi personal ini dapat dimanfaatkan untuk menjelaskan kesalahan siswa, mengurangi sikap agresif dan mendapat approval dari siswa, serta dapat menumbuhkembangkan rasa memiliki di kalangan siswa. Pemberian pujian dan self evaluation dapat digunakan sebagai langkah awal untuk mengembangkan rasa memiliki. Tidak bisa dipungkiri bahwa pemberian reward yang menarik bagi siswa menjadi strategi yang paling efektif dalam membantu siswa menyesuaikan sikap. Berbagai bentuk tugas dapat diberikan apabila terdapat pelanggaran aturan kelas oleh siswa. tugas tersebut dapat dikerjakan secara mandiri, kolaborasi dengan guru, bahkan dapat dikolaborasikan dengan "lawan bertengkar" siswa. Penanaman pemahaman tentang berbagi sesuatu yang baik kepada teman merupakan cara untuk mengurasi sikap egosentris siswa. Siswa bisa mendapatkan gambaran tugas secara jelas apabila terdapat contoh tugas yang dapat dimasukkan pada kriteria baik. Contoh tugas tersebut dapat dilakukan dengan memberikan contoh dari tugas siswa lain yang telah selesai terlebih dahulu. Apabila semua strategi sebelumnya pernah dilakukan, strategi nonverbal dapat diterapkan tanpa harus menggunakan strategi lisan, misalnya cukup hanya melihati siswa ketika melakukan pelanggaran. Strategi guru disajikan pada tabel 1.

Dua jenis strategi dapat dilakukan untuk untuk membantu siswa dalam menyesuaikan sikap ketika memasuki tahun pertama di sekolah dasar (Tabel 1). Strategi verbal mendominasi untuk diterapkan pada siswa sekolah dasar pedesaan daripada strategi nonverbal. Sembilan strategi dapat dilakukan dalam bentuk komunikasi linsan. Hanya satu jenis komunikasi nonverbal yang dapat dilakukan untuk membantu siswa dalam menyesuaikan sikap. Jenis strategi nonverbal hanya bisa digunakan bila strategi verbal telah pernah dilakukan sebelumnya.

Strategi pertama merupakan diseminasi peraturan dalam kelas, salah satunya adalah aturan untuk berbicara. Pendeklarasian aturan untuk berbicara sangat bagus bila disampaikan di awal masuk kelas. Sesekali bila siswa lupa, bisa diingatkan selama proses pembelajaran. Pembiasaan ini berdampak baik pada pembentukan karakter untuk saling menghargai kepada pihak lain untuk mengutarakan pendapat (Nurshat et al., 2021). Pemberian reward and punishment sangat penting agar aturan yang telah disepakati dapat terus dilaksanakan (Wilders \& Levy, 2021).

Strategi kedua, pemanfaatan komunikasi interpersonal yang intens dapat memberikan dampak yang bagus pada pembiasaan sikap siswa kelas satu sekolah dasar. Melalui kedekatan komunikasi, guru dapat memberikan penjelasan terhadap kesalahan yang dilakukan siswa. komunikasi yang hangat juga dapat mengurangi bahkan meniadakan sikap agresif dan sekaligus mampu mendapatkan persetujuan dari siswa yang melanggar aturan kelas. Di sisi lain, komunikasi interpersonal secara tepat, dapat mengembangkan rasa memiliki segala sesuatu yang ada di kelas sehingga tanpa diminta siswa akan menjaga peralatan kelas. Komunikasi interpersonal yang sehat dapat menciptakan suasana kondusif di kelas dan sekolah (Triwardhani et al., 2020).

Strategi ketiga yang dapat dilakukan guru adalah pemberian pujian dan meminta siswa untuk melakukan self evaluation. Pemberian pujian juga mampu mengurangi sikap yang melanggar aturan, terutama di tingkat sekolah dasar (Haydon et al., 2020). Selain fungsi tersebut, keterikatan emosional guru dan siswa juga dapat dipupuk melalui pemberian pujian 
oleh guru (Mason et al., 2020). Siswa mendapat skor kompetensi yang tinggi juga dapat dihubungkan dengan umpan balik positif yang diberikan guru melalui pujian (Oinas et al., 2020).

Tabel 1. Strategi guru membatu siswa melakukan penyesuaian sikap

\begin{tabular}{cl}
\hline $\begin{array}{c}\text { Jenis } \\
\text { Strategi }\end{array}$ & \multicolumn{1}{c}{ Strategi } \\
\hline Verbal & Aturan untuk ijin berbicara \\
& Komunikasi interpersonal \\
& Pemberian pujian dan self evaluation \\
& Menjanjikan reward \\
& Pemberian tugas kepada siswa tipe 1: Dikerjakan bersama dengan \\
& "lawan" \\
& Pemberian tugas kepada siswa tipe 2: Dikerjakan bersama dengan guru \\
& Pemberian tugas kepada siswa tipe 3: Dikerjakan secara mandiri \\
& Konsep sharing is caring \\
& Pemberian contoh dan acuan dari teman sebaya \\
\hline Nonverbal & Melihati siswa \\
\hline
\end{tabular}

Menjanjikan reward merupakan strategi keempat yang terbukti sangat efektif membantu siswa dalam melakukan penyesuaian sikap. Siswa menjadi sangat termotivasi dalam menyelesaikan tugas yang diberikan, namun tugas yang diberikan juga harus dapat menarik siswa. Pemberian reward dapat berbentuk tepuk tangan, penghargaan, memajang hasil kerja siswa yang terbaik, atau memajang foto dan ucapan selamat pada papan majalah dinding (Aningsih et al., 2022). Pemberian reward secara berkelompok juga terbukti efektif dapat menunjang kompetensi siswa (Begeny et al., 2020). Guru juga tidak perlu terlalu lama menjelaskan topik pembelajaran asalkan terdapat reward dan penguatan diberikan kepada siswa (Wah \& Sim, 2020). Di lain pihak, Saat \& Özenç (2022) membuktikan bahwa implementasi self evaluation dapat meningkatkan kompetensi siswa dalam bidang kebahasaan dan dapat mengembangkan kepuasan dalam belajar (Martínez et al., 2020).

Pemberian tugas kepada siswa dapat dikerjakan bersama "lawan", guru, atau mandiri. Strategi ini merupakan strategi lima, enam, dan tujuh. Penyelesaian tugas secara berkelompok melalui platform online mayoritas tidak disukai oleh siswa (Nazilah et al., 2021). Sedikit berkebalikan, Majewska \& Vereen (2021) menyampaikan bahwa pemberian tugas secara berkelompok dapat mendorong terjadinya kolaborasi, komunikasi yang intens, dan kehadiran sosial. Sejalan dengan hal ini, ternyata tugas yang diselesaikan secara mandiri juga dapat mengembangkan kompetensi siswa untuk berinovasi (Usher et al., 2021). Penggunaan tugas individu juga dianggap lebih fleksibel karena tidak melibatkan banyak siswa dalam satu kelompok (Fischer, 2021).

Penanaman konsep sharing is caring merupakan strategi kedelapan. Strategi ini perlu pembiasaan, tidak dapat dilakukan sekali langsung terlihat dampaknya. Penanaman konsep ini juga dapat dilakukan melalui permainan, misalnya Angklung (Nuraida \& Milyartini, 2016) dan "boy-boyan" (Saleh et al., 2017). Penanaman konsep ini juga dapat dilakukan dengan mengintegrasi media dongeng berbasis visual (Nuraida \& Milyartini, 2016) pada pembelajaran.

Pemberian contoh dan acuan dari teman sebaya dijadikan strategi terakhir pada jenis strategi verbal. Pemberian contoh-contoh tugas dari siswa lain yang dianggap baik merupakan strategi yang umum digunakan di kalangan guru yang mengajar siswa pada usiausia dini (Ramdhani et al., 2019; Surya, 2017). Melalui strategi ini, siswa memiliki gambaran riil terkait tugas yang dianggap sesuai dengan kriteria penilaian guru. Siswa menjadi lebih 
mudah untuk menyelesaikan tugasnya sendiri karena sudah memiliki acuan dari teman sebayanya.

Satu-satunya strategi nonverbal yang dipakai dalam kasus ini adalah dengan melihati siswa. strategi ini bisa diterapkan asalkan strategi verbal sudah pernah dilakukan. Komunikasi nonverbal yang efektif dapat membuat suasana pembelajaran menjadi kondusif (Sholikhah, 2020). Ayu (2020) menyarankan lebih banyak menggunakan bahasa tubuh pada anak usia dini. Melihat pentingnya komunikasi nonverbal ini, guru dituntut untuk terus mengembangkan kompetensi komunikasi nonverbal yang disesuaikan dengan perkembangan budaya yang ada (Ambarawati, 2021).

Riset ini memiliki sejumlah keterbatasan dalam pelaksanaannya di lapangan. Paper ini memberikan gambaran strategi guru kelas satu sekolah dasar pedesaan dengan segala keterbatasan, untuk dapat membatu siswa melakukan penyesuaian sikap. Penelitian ini tidak membahas terkait dengan kenapa siswa tersebut melakukan pelanggan. Untuk itu, penelitian selanjutnya diharapkan dapat melanjutkan riset terkait dengan alasan siswa melakukan pelanggaran. Riset selanjutnya juga dapat diterapkan pada sekolah dasar inklusif.

\section{SIMPULAN}

Strategi guru membantu siswa beradaptasi dengan lingkungan baru berdampak pula pada kedekatan emosional guru dan siswa. Guru dapat mendahulukan komunikasi verbal sebagai strategi utama dalam membantu siswa. Bila usaha tersebut tidak kunjung berhasil atau bahkan dikatakan gagal, maka guru dapat menggunakan strategi nonverbal. Terdapat 10 strategi yang dapat membantu guru dalam melakukan penyesuaian sikap siswa. Strategi tersebut terbagi menjadi dua jenis, yaitu strategi verbal dan nonverbal. Strategi verbal yang dapat dilakukan adalah ijin guru terlebih dahulu sebelum berbicara, komunikasi personal, memberi pujian dan melakukan self evaluation, memberikan penghargaan, pemberian tugas yang dikerjakan oleh "lawan", guru, dan mandiri, dan menanamkan pemahaman berbagi. Melihati siswa merupakan strategi nonverbal yang dapat dilakukan guru untuk menyesuaikan sikap siswa.

\section{UCAPAN TERIMA KASIH}

Penulis mengucapkan terima kasih kepada Universitas Nahdlatul Ulama Surabaya atas segala dukungan dalam penyelesaian penelitian ini.

\section{DAFTAR PUSTAKA}

Ambarawati, A. (2021). Urgensi Keterampilan Komunikasi Nonverbal Guru Pada Era Society 5.0. Jurnal Darussalam: Jurnal Pendidikan, Komunikasi Dan Pemikiran Hukum Islam, 12(2).

Aningsih, Zulela, M. S., Neolaka, A., Iasha, V., \& Setiawan, B. (2022). How is the Education Character Implemented? The Case Study in Indonesian Elementary School. Journal of Educational and Social Research, 12(1), 371-380. https://doi.org/10.36941/jesr-2022-0029

Aspelin, J., Östlund, D., \& Jönsson, A. (2021). Pre-Service Special Educators' Understandings of Relational Competence. Frontiers in Education, 6. https://doi.org/10.3389/feduc.2021.678793

Ayu, P. E. S. (2020). Pentingnya Pemahaman Bahasa Tubuh Bagi Para Guru Pendidikan Anak Usia Dini. Purwadita: Jurnal Agama Dan Budaya, 3(2), 29-36. https://doi.org/10.31849/paud-lectura.v3i01.3340

Ayuwanti, I., Marsigit, \& Siswoyo, D. (2021). Teacher-student interaction in mathematics learning. International Journal of Evaluation and Research in Education, 10(2), 660-667. https://doi.org/10.11591/ijere.v10i2.21184

Azwar, B., Wanto, D., \& Hidayat, R. (2021). Improving Self-Resilience in Students with Special Needs through the Counseling Teachers' Roles: A Case Study on Grounded Theory. Education Research International, 2021, 1-6. https://doi.org/10.1155/2021/7872889 
Begeny, J. C., Codding, R. S., Wang, J., Hida, R. M., Patterson, S. L., Kessler, S., Fields-Turner, F., \& Ramos, K. A. (2020). An analysis of motivation strategies used within the small-group Accelerating Mathematics Performance through Practice Strategies (AMPPS-SG) program. Psychology in the Schools, 57(4), 540-555. https://doi.org/10.1002/pits.22334

Chirinda, B. (2021). Professional development for teachers' mathematical problem-solving $\begin{array}{lllll}\text { pedagogy - } \quad \text { what } & \text { counts? }\end{array}$ https://doi.org/10.4102/pythagoras.v42i1.532

Cook, K. D. M., Dearing, E., \& Zachrisson, H. D. (2017). Information sharing between teachers and early education programs during school entry in Norway: associations with children's school adjustment and success in the first year. International Journal of Child Care and Education Policy, 11(1). https://doi.org/10.1186/s40723-017-0039-5

Coşkun, K., \& Kara, C. (2020a). What Happens During Teacher-Student Interaction in the First Year of Primary School? A New Explanation. SAGE Open, 10(2). https://doi.org/10.1177/2158244020926566

Coşkun, K., \& Kara, C. (2020b). What Happens During Teacher-Student Interaction in the First Year of Primary School? A New Explanation. SAGE Open, 10(2). https://doi.org/10.1177/2158244020926566

Dockett, S., \& Perry, B. (2013). Trends and tensions: Australian and international research about starting school. International Journal of Early Years Education, 21(2-3), 163-177. https://doi.org/10.1080/09669760.2013.832943

Fischer, K. M. (2021). Using critical analysis of scientific literature to maintain an interactive learning environment for in-person and online course modalities. Journal of Microbiology and Biology Education, 22(2). https://doi.org/10.1128/jmbe.v22i1.2523

Haydon, T., Musti-Rao, S., Kennedy, A., Murphy, M., Hunter, W., \& Boone, J. (2020). Using Teacher Praise With Middle and High School Students. Beyond Behavior, 29(2), 108-115. https://doi.org/10.1177/1074295620915883

Huguette, S. B. (2021). A Comparative Study on Rural Teacher Education in Three Developing Countries: Myanmar, Democratic Republic of Congo And Tanzania. Indonesian Journal of Creative Counseling, 1(2), 43-60. https:// doi.org/10.47679/ijcc.v1i2.131

Hung, C., Chen, T., \& Lee, Y. (2021). From Cultural Heritage Preservation to Art Craft Education : A Study on Taiwan Traditional Lacquerware Art Preservation and Training. Education Sciences, 11, 801. https:// doi.org/10.3390/educsci11120801

Jafari, S., \& Asgari, A. (2020). Predicting Students' Academic Achievement Based on the Classroom Climate, Mediating Role of Teacher-Student Interaction and Academic Motivation. Integration of Education, 24(1), 62-74. $\quad \underline{\text { https://doi.org/10.15507/1991- }}$ 9468.098.024.202001.062-074

KIAT Guru. (2019). Primary Education in Remote Indonesia: Survey Results from West Kalimantan and East Nusa Tenggara. In World Bank Publications (Issue December).

Kim, J., Lee, J., \& Lee, T. J. (2021). The sustainable success and growth of social ventures: Their internal and external factors. Sustainability (Switzerland), 13(9), 1-19. https://doi.org/10.3390/su13095005

Liu, H., \& Gillies, R. M. (2021). Teacher Questions: Mediated-Learning Behaviors Involved in Teacher-Student Interaction During Whole-Class Instruction in Chinese English Classrooms. Frontiers in Education, 6. https:// doi.org/10.3389/feduc.2021.674876

Majewska, A. A., \& Vereen, E. (2021). Fostering student-student interactions in a first-year experience course taught online during the covid-19 pandemic. Journal of Microbiology and Biology Education, 22(2). https://doi.org/10.1128/jmbe.v22i1.2417

Martínez, V., Mon, M. A., Álvarez, M., Fueyo, E., \& Dobarro, A. (2020). E -Self-Assessment as a Strategy to Improve the Learning Process at University. Education Research International, 2020. https://doi.org/10.1155/2020/3454783

Mason, R. A., Wills, H. P., Irvin, D., Jia, F., \& Kamps, D. M. (2020). Ecobehavioral Assessment of Paraeducator Behaviors That Support Engagement of Students With Disabilities. Exceptional Children, 86(4), 413-429. https://doi.org/10.1177/0014402919893693 
Nazilah, A., Ibrahim, C. W., Rohaizad, N. A. A., Norillah, A., Ibrahim, R. Z. A. R., \& Dagang, M. (2021). Counselling students' perception of online learning during COVID-19 in Malaysia. Electronic Journal of E-Learning, 19(4), 282-295. https:// doi.org/10.34190/ejel.19.4.2445

Ng, D. T. K., \& Chu, S. K. W. (2021). Motivating students to learn ai through social networking sites: A case study in Hong Kong. Online Learning Journal, 25(1), 195-208. https://doi.org/10.24059/olj.v25i1.2454

Nuraida, E., \& Milyartini, R. (2016). Meningkatkan Keterampilan Sosial Anak Usia Dini melalui kegiatan Bermain Angklung (Penelitian Tindakan kelas di TK Laboratorium Percontohan Universitas Pendidikan Indonesia). Swara: Jurnal Antologi Pendidikan Musik, IV(2), 1-14.

Nurshat, A., Almazhai, Y., Laura, B., Begakhmet, A., Zhorabekova, A., Bagdat, B., \& Elmira, U. (2021). Competences given to disabled students within the scope of inclusive education. World Journal on Educational Technology: Current Issues, 13(4), 696-706. https://doi.org/10.18844/wjet.v13i4.6256

Ocak, G., \& Karakuyu, A. (2022). Investigation of The Relationship Between Lifelong Learning and Epistemological Beliefs of Associate Degree Students'. Participatory Educational Research, 9(2), 136-149. https://doi.org/10.17275/per.22.33.9.2

Oinas, S. E., Thuneberg, H., Vainikainen, M.-P., \& Hotulainen, R. (2020). Technology-enhanced feedback profiles and their associations with learning and academic well-being indicators in basic education. Contemporary Educational Technology, 12(2), 1-16. https://doi.org/10.30935/cedtech/8202

Oswald, K., \& Zhao, X. (2021). Collaborative Learning in Makerspaces: A Grounded Theory of the Role of Collaborative Learning in Makerspaces. SAGE Open, 11(2). https://doi.org/10.1177/21582440211020732

Park, H. J. (2021). "I Kept Questioning It in the First 6th Months": The Process of AAC Acceptance in Parents of Children with Complex Communication Needs. Communication Sciences and Disorders, 26(1), 120-136. https://doi.org/10.12963/csd.21801

Perry, B., Dockett, S., \& Petriwskyj, A. (2013). Transitions to school-international research, policy and practice (Vol. 9). Springer. https:// doi.org/10.1007/978-94-007-7350-9

Ramdhani, S., Yuliastri, N. A., Sari, S. D., \& Hasriah, S. (2019). Penanaman Nilai-Nilai Karakter melalui Kegiatan Storytelling dengan Menggunakan Cerita Rakyat Sasak pada Anak Usia Dini. Jurnal Obsesi: Jurnal Pendidikan Anak Usia Dini, 3(1), 153-160. https://doi.org/10.31004/obsesi.v3i1.108

Rulyansah, A. (2021). Integrasi Realistic Mathematics Education dan Multiple Intelligences pada Siswa Sekolah Dasar. ELSE (Elementary School Education Journal, 5(1), 45-54. https:// doi.org/10.30651/else.v5i1.7336

Rulyansah, A., Asmarani, R., \& Mariati, P. (2022). Peningkatan Creative Thinking melalui Creative Problem-Solving Berorientasi Multiple Intelligence: Kajian pada Bidang Matematika $\begin{array}{llll}\text { Sekolah Dasar. Jurnal 6(1), Basicedu, 109-115. } & \text {. }\end{array}$ https://doi.org/10.31004/basicedu.v6i1.1925 ISSN

Rulyansah, A., Asmarani, R., Mariati, P., \& Rahmawati, N. D. (2022). Kemampuan Guru Junior dalam Mengajarkan Proses Berpikir untuk Menyelesaikan Soal Cerita Sederhana: Studi pada Guru Matematika Sekolah Dasar. Jurnal Basicedu, 6(1), 203-213.

Saat, F., \& Özenç, E. G. (2022). Effect of Self-Evaluation-Based Oral Reading Method in Elementary School on Reading Fluency and Reading Comprehension. Participatory Educational Research, 9(2), 437-462. https://doi.org/10.17275/per.22.48.9.2

Saleh, Y. T., Nugraha, M. F., \& Nurfitriani, M. (2017). Model permainan tradisional "boy-boyan" untuk meningkatkan perkembangan sosial anak SD. ELSE (Elementary School Education Journal): Jurnal Pendidikan Dan Pembelajaran Sekolah Dasar, 1(2b).

Samuel, K. B., \& Dudu, W. T. (2018). In search of a working strategy: The AHA... moment in the teaching of science subjects at two South African high schools. Eurasia Journal of Mathematics, Science and Technology Education, 14(8). https://doi.org/10.29333/ejmste/91921

Sholikhah, A. (2020). Komunikasi nonverbal dalam proses pembelajaran pada pendidikan Anak Usia Dini. UIN Sunan Ampel Surabaya. 
Sun, L., Ruokamo, H., Siklander, P., Li, B., \& Devlin, K. (2021). Primary school students' perceptions of scaffolding in digital game-based learning in mathematics. Learning, Culture and Social Interaction, 28, 100457. https://doi.org/10.1016/j.lcsi.2020.100457

Surya, Y. F. (2017). Penggunaan Model Pembelajaran Pendidikan Karakter Abad 21 \pada Anak Usia Dini. Jurnal Obsesi: Jurnal Pendidikan Anak Usia Dini, 1(1), 52-61. https://doi.org/10.31004/obsesi.v1i1.31

Tabatabaei, O., \& Assefi, F. (2012). The effect of portfolio assessment technique on writing performance of EFL learners. English Language Teaching, 5(5), 138-147. https://doi.org/10.5539/elt.v5n5p138

Tayyaba, S. (2012). Rural-urban gaps in academic achievement, schooling conditions, student, and teachers' characteristics in Pakistan. International Journal of Educational Management, 26(1), 6-26. https://doi.org/10.1108/09513541211194356

Triwardhani, I. J., Trigartanti, W., \& Putra, R. P. (2020). Study of communication ethnography for entrepreneurship culture in the interpersonal relations of teachers and students. Jurnal Komunikasi: Malaysian Journal of Communication, 36(1), 109-123. https:// doi.org/10.17576/JKMJC-2020-3601-07

Usher, M., Barak, M., \& Haick, H. (2021). Online vs. on-campus higher education: Exploring innovation in students' self-reports and students' learning products. Thinking Skills and Creativity, 42. https://doi.org/10.1016/j.tsc.2021.100965

Wah, F., \& Sim, T. N. (2020). Effects of reward pedagogy on spelling scores and prosocial behaviors in primary school students in Singapore. Educational Psychology, 40(3), 349-366. https://doi.org/10.1080/01443410.2019.1662888

Wang, X., Sun, H., \& Li, L. (2019). An Innovative Preschool Education Method Based on Computer Multimedia Technology. International Journal of Emerging Technologies in Learning (IJET), 14(14), 57. https://doi.org/10.3991/ijet.v14i14.10714

Wilders, C., \& Levy, R. (2021). 'I don't really like the thing what you do, I like it more because you get the stickers': the impact of rules and rewards on children's transition experiences. International Journal of Early Years Education, 29(4), 391-404. https:// doi.org/10.1080/09669760.2020.1759401

Xiang, X., Wu, Q., Zhang, Y., Zhu, B., Wang, X., Wan, A., Huang, T., \& Hu, L. (2021). A pedagogical approach to incorporating the concept of sustainability into Design-To-PhysicalConstruction teaching in introductory architectural design courses: A case study on a Bamboo construction project. Sustainability (Switzerland), 13(14). https://doi.org/10.3390/su13147692

Zhang, S. (2021). A Novel Teaching Approach for Mobile Internet-Based Collaborative Knowledge Construction in "Teaching Management." International Journal of Emerging Technologies in Learning (IJET), 16(12), 51. https://doi.org/10.3991/ijet.v16i12.23223

Zhou, T., Law, R., \& Lee, P. C. (2021). Exploring sustainable measurements of academic research: How do faculty members in teaching-oriented universities of china evaluate good research in tourism and hospitality? Sustainability (Switzerland), 13(20). https://doi.org/10.3390/su132011129

Zydziunaite, V., Kaminskiene, L., \& Jurgile, V. (2021). Teachers' Abstracted Conceptualizations of Their Way in Experiencing the Leadership in the Classroom: Transferring Knowledge, Expanding Learning Capacity, and Creating Knowledge. Education Sciences, 11(12), 782. https://doi.org/10.3390/educsci11120782 